\title{
Perception of Health Promotion Practices Among the Faculty of Selected University, Ras Al Khaimah, United Arab Emirates
}

\author{
Rekha Jaiprakash Ogale ${ }^{1}$, Rabab Gad Abd El- Kadre ${ }^{1,3}$, Vijaya Kumardhas ${ }^{1}$, Padma Gurumadhav Rao ${ }^{2}$, Sathvik \\ B. Sridhar ${ }^{2} \&$ Maragatham Kannan ${ }^{1}$ \\ ${ }^{1}$ RAK College of Nursing, RAK Medical and Health Sciences University, United Arab Emirates \\ ${ }^{2}$ RAK College of Pharmaceutical Sciences, RAK Medical and Health Sciences University, United Arab \\ Emirates \\ ${ }^{3}$ Community Health Nursing Department, Faculty of Nursing, Mansoura University, Egypt \\ Correspondence: Dr. Rekha Jaiprakash Ogale, Professor, RAKCON, RAK Medical \& Health Sciences \\ University, Near RAK Hospital, Ras Al Khaimah, United Arab Emirates.
}

Received: June 30, 2019

doi:10.20849/ijsn.v4i3.624
Accepted: August 19, 2019

Online Published: August 27, 2019

URL: https://doi.org/10.20849/ijsn.v4i3.624

\begin{abstract}
Background and aim: Health promotion is one of the vital and key element for a healthy living. The health care professional spent their initial developing years in learning about health and thereafter training and imparting knowledge to their students and people to whom they serve. The faculty of health sciences are the educators who not only teach health promotion to their students but also educate and prepare the students for the health promotion of the society. Aim: The purpose of the study was to assess the perception of health promotion and health promotion practices existing among the faculty of Medical and Health Sciences University, Ras Al Khaimah, UAE.

Study design: The study was descriptive and cross sectional. Data was collected using convenience sampling technique. Self-administered questionnaire was used for data collection. The sample size of the study was 52 .

Results: Of the total 52 respondents, majority were females, 31-50 years old (63\%), married (87\%) from nursing and medical faculty ( $63 \%)$, non arabic (77\%), with 20 or less years of total professional experience $(62 \%)$. About $52 \%$ of the faculty reported that their daily routine comprises sitting at one place for 6-10 hours. Majority (98\%) of the participant felt that health promotion is most important for healthy living and is the best resource for everyday life (100\%). However majority $(60 \%)$ of the faculty reported that they do not find time to perform health promotion activities especially daily physical exercises and only $39 \%$ were actually able to perform their daily exercises.
\end{abstract}

CONCLUSION: Though health promotion activities are most important for healthy living, the physical exercises as essential health promotion activities are not practiced by the health sciences university faculty.

Keywords: perception, health promotion, practice, faculty, university

\section{Introduction}

Living a healthy lifestyle is a fundamental requirement to achieve optimal mental and physical well-being. Healthy lifestyle involves individuals controlling all behavior that might affect their health and adopt to those behaviors that serve to maintain and raise individuals' own wellness level. (Walker, Sechrist \& Pender, 1987). Health promotion is the initial and primary level of health prevention that lies in the hands of the individual. Individual's positive mental attitude towards performing the day to day practice of healthy behavior in life strengthen his health. Wellness is the whole of behaviours oriented towards becoming healthy at an optimal level. The researches have shown that many diseases encountered in adulthood can be prevented with an effective and healthy lifestyle. Health problems such as heart attacks, paralysis, chronic respiratory disorders and cancers may actually be prevented by healthy living habits established in the early years. (Amuna \& Zotor, 2008; Danaei et al., 2009)

Today the incidences of noncommunicable diseases (NCDs) are on rise leading into several complications. NCDs are the leading cause of death globally, and one of the major health challenges of the 21 st century (WHO, 
2018). Healthy lifestyle is the single most important factor in prevention and control of the health problems among people including NCDs. (Arena et al., 2015). The health care professionals need to propagate the practice of health promoting behavior to the people. For this, they need to get equipped with all those tools and techniques that strengthen their ability to be good educators. The faculty of health sciences involved in educating health care professionals need to use the motivational strategies to prepare their pupils as the practitioners of health promotion for self and others who will be the future health care force of the society. To do this job the faculty themselves must practice the health promotion behavior in their day to day life.

World Health Organization (WHO, 1996) defines health promotion as the 'Process of enabling people to increase control over, and to improve, their health. In this era of development, where stress and chronic diseases among people have reached to its highest levels, health promotion becomes the most economical and perfect solution for remaining healthy and enjoying highest quality of life. Health-promoting self-care behavior emphasizing positive lifestyle practices improves the health and quality of life of adults (Action \& Malathun, 2000).

Health promotion is a key investment and an essential element of health development and moves beyond a focus on individual behavior to a wide range of social and environmental interventions. (WHO, 2017) People who are more fulfilled and contented with themselves and their lives have physical need satisfaction and positive connections with others and are able to make better decisions regarding positive health promoting self- care behaviors. (Gayle \& Porntip, 2000)

It has been found that health professionals with positive attitudes towards physical activity were more likely to promote physical activity to their clients (Loprinzi \& Beets, 2014). The health science faculties are responsible to develop health care manpower for the nation who would function as responsible professionals in promoting health of their clients and the communities. Faculty who themselves believes and practices health promotion are more likely to motivate and teach health promotion behaviors to the students. Most of the studies indicate that the health care professionals do not practice health promotion activities in actuality. According to Frank, Dresner, Shani, \& Vinker, (2013), improving the physical health of medical students and physicians is most important to encourage prevention oriented health care systems for the patients and the community. The health care workers are not more likely to participate in worksite health promotion program compared to what has been reported for other working populations and despite a supposedly good knowledge of health-related issues, health care workers reporting relatively unfavorable lifestyles are not more motivated to participate. As health care workers are key actors in promoting healthy lifestyles to other groups, such as patients, it is of utmost importance to find strategies to engage this professional group in activities that promote their own health. (Ingibjörg, Jonsdottir, Börjesson \& Ahlborg, 2011)

It has been identified that the nurses had the worst health behaviors and lowest participation in health promotion activities of all occupational groups working in hospitals. (Shu-Ti, Jen-Huai, Nicole, \& Li-Yin, 2014) Many registered nurses are not achieving the recommended daily levels of physical activity and there is a need for training on physical activity related counselling, including awareness of the latest recommendations and strategies to promote physical activity. (Bakhshi, Sun, Murrells, \& While, 2015) Physicians especially men reported many common chronic illnesses as often as or more often than other employees. Physicians had consulted other medical professionals less often than other employees, and they primarily self- treated their illnesses. (Toyry, Rasanen, Kujala, Aarimaa, \& Juntunen, 2000) Additional interventions designed to improve physicians' lifestyles and personal health behaviors is most important. It is also suggested that focus on creating healthy lifestyles will benefit physicians as much as the general population. (Bazargan, Makar, Bazargan-Hejazi, Ani \& Wolf, 2009)

Sometimes in life the health science professionals themselves suffer with various health problems and have no regular source of care. Not having a regular source of care is significantly associated with failure to use preventive services several years later. (Gross, Mead, Ford \& Kla, 2000) Academic members of health sciences do face occupational stress and burn out and to improve their psychological health, there should be some strategies to decrease stress and determining stress resources. (Hedayat et al., 2016) Health promotion activities are the best such strategies to maintain health and minimize stress in life. However in reality a reasonably high proportion of physicians, nurses, and community health workers report not engaging in healthy lifestyle behaviors that impact chronic diseases. (Karen et al., 2016)

The faculty who practice health promotion in their life may teach and train the health sciences students in a better way as training health professionals in how to convey all relevant information about physical activity to their patients is critical for health promotion (Burdick et al., 2015).

Therefore it can be concluded that health prevention is most important function of the health care professionals 
amongst all. Health promotion is the cornerstone for healthy living. The faculty of health sciences who train the health manpower have pivotal role in not only promoting their health but preparing the health professionals who would in turn emphasize health promotion behavior among the populations.

\subsection{Aim / Objectives}

1. To assess the perception of health promotion among the faculty of Ras Al Khaimah Medical and Health Sciences University.

2. To identify the existing health promotion practices among the faculty of Ras Al Khaimah Medical and Health Sciences University.

3. To identify an association between selected demographic variables \& health promotion perception and practices among the faculty of Ras Al Khaimah Medical and Health Sciences University.

\subsection{Research Questions}

1. What is the perception of health promotion among the faculty of Ras Al Khaimah Medical and Health Sciences University?

2. What are the existing health promotion practices among the faculty of Ras Al Khaimah Medical and Health Sciences University?

3. Is there an association between selected demographic variables \& health promotion practices among the faculty of Ras Al Khaimah Medical and Health Sciences University?

\section{Method}

\subsection{Study Setting and Population}

The setting of the study was Ras Al Khaimah Medical \& Health Sciences University (RAKMHSU) and the population of the study was faculty of the four constituent colleges of RAKMHSU viz: Medical, Nursing, Pharmacy and Dental. The RAKMHSU is the first comprehensive health Science University of the Country fully owned and managed by the Government of Ras Al Khaimah. RAKMHSU has 1300 plus students from 48 different nationalities, 109 full time teaching faculty, 113 adjunct faculty and 96 non-teaching staff hailing from 26 different countries. The sample of the study constituted faculty of RAKMHSU, Ras Al Khaimah, UAE who fulfilled the inclusion criteria. The convenient sampling method was used. The inclusion criteria for the study sample was the regular faculty who are willing to participate in the study and sign the written consent. Exclusion criteria was the adjunct faculty and the faculty on long leave during data collection period.

\subsection{Design}

A descriptive cross sectional study was conducted in RAKMHSU.

\subsection{Data Collection}

After the approval from RAKMHSU Research and Ethics Committee, the deans of the constituent four colleges were approached for their permission. The faculty in each college was approached thereafter. They were explained about the purpose of the research and the process of data collection.

The data collection tool was self-structured questionnaire that was constructed based on the review of World Health Organization's health promotion information and similar online tools. It comprised three main sections.

Section I: Demographic data- included 10 variables: age, gender, marital status, type of faculty, ethnicity, years of experience in RAKMHSU, total years of professional experience, existing chronic health problems, consumption tobacco in any form and alcohol consumption.

Section II: Perception of Health Promotion (PHP): this section included 17 points on perception of health promotion rated on Likert scale from 5 to 1 . The perceptions less than 65 were scored as unsatisfactory: $<65(0-$ $55)$ whereas the perceptions more than or equal to 65 were scored as satisfactory: $\geq 65$ (55.1 -85).

Section III: this section comprised Health Promotion Practices (HPP) with 18 points on practice of health promotion. The practice of health promotion was scored as: 3 for yes, 2 for sometimes and 1 for no. The levels of faculty practice score were classified as: Unsatisfactory with the scores less than $65:<65(0-35)$ and Satisfactory if the scores were more than or equal to $65: \geq 65(35.1-54)$.

\subsection{Validity and Reliability}

The content validity of the instrument was carried out by the experts from the education, nursing and medical fields. The Cronbach alpha for reliability was estimated as 0.79 . 


\subsection{Pilot Study}

A feasibility study on 10 faculty members was conducted

\subsection{Procedure}

Data was collected from the faculty by using self-administered Health Promotion perception and Practices tool. (HPPPT). After their consent the questionnaire (HPPPT) was explained and handed over to them. The faculty were requested to return the filled questionnaire within two weeks' time. The questionnaire was distributed among the 110 faculty of the four constituent colleges viz, Medical, Dental, Nursing and Pharmacy. The final filled forms received from the faculty were 55 . Three forms were incomplete so they discarded. The data collection was carried out from September 2017 to September 2018.

\subsection{Ethical Considerations}

Ethical approval was obtained from the Research and Ethics Committee of the university. The faculty were explained about the process of research and data collection. On their acceptance of participation, they were asked to sign the consent form. The faculty were assured of the anonymity and confidentiality that will be maintained of the information given by them.

\subsection{Data Analysis}

Data was analyzed using descriptive statistics like frequency and percentage to assess the perception and practices and inferential statistics, Chi square was used to find the association between selected demographic variables and health promotion perception and practices among the faculty. The analysis was carried out using Statistical Package for the Social Sciences (SPSS) version 23.

\section{Results}

\subsection{Demographic Characteristics}

Table 1. Demographic characteristics of the study group $(n=52)$

\begin{tabular}{lll}
\hline Items & N & \% \\
\hline Faculty & 14 & 26.9 \\
Medical & 19 & 36.5 \\
Nursing & 9 & 17.3 \\
Pharmacy & 10 & 19.3 \\
Dental & & \\
\hline Age / years & 27 & 51.9 \\
$<40$ & 25 & 48.1 \\
$\geq 40$ & & \\
\hline Gender & 19 & 36.54 \\
Male & 33 & 63.46 \\
Female & & \\
\hline Marital status & 45 & 86.54 \\
Married & 7 & 13.46 \\
Unmarried & & \\
\hline Ethnicity & 12 & 23.08 \\
Arab & 40 & 76.92 \\
Non-Arab & & \\
\hline Years of experience & 28 & 53.85 \\
\hline 5 & 24 & 46.15 \\
$\geq 5$ & & \\
\hline Place of residence & 43 & 82.69 \\
Ras Al-Khaimah & 9 & 17.31 \\
Out of Ras Al-Khaimah & 17 & 32.7 \\
\hline Number of hours sitting/day & 27 & 51.9 \\
1 - 5 & 8 & 15.4 \\
\hline - 10 & & \\
\hline
\end{tabular}


As shown in Table 1, out of total 52 respondents, majority were females $(63 \%)$, in the age group of 31-50 years $(63 \%)$, married $(87 \%)$ and mostly were nursing and medical faculty $(63 \%)$. About $37 \%$ faculty belonged to dental and pharmacy colleges. Majority (77\%) of the faculty were of non- arabic ethnicity. About $54 \%$ of the faculty had less that 5 years teaching experience at RAKMHSU(54\%) Most of the faculty (83\%) were residing at Ras al Khaimah.

As far as faculty's physical movement througout the day is concerned, $52 \%$ of the faculty stated that their job demands sitting for 6-10 hours at one place per day and 15\% said that they sit at one place for more than 10 hours per day.

Existing health problems among the faculty

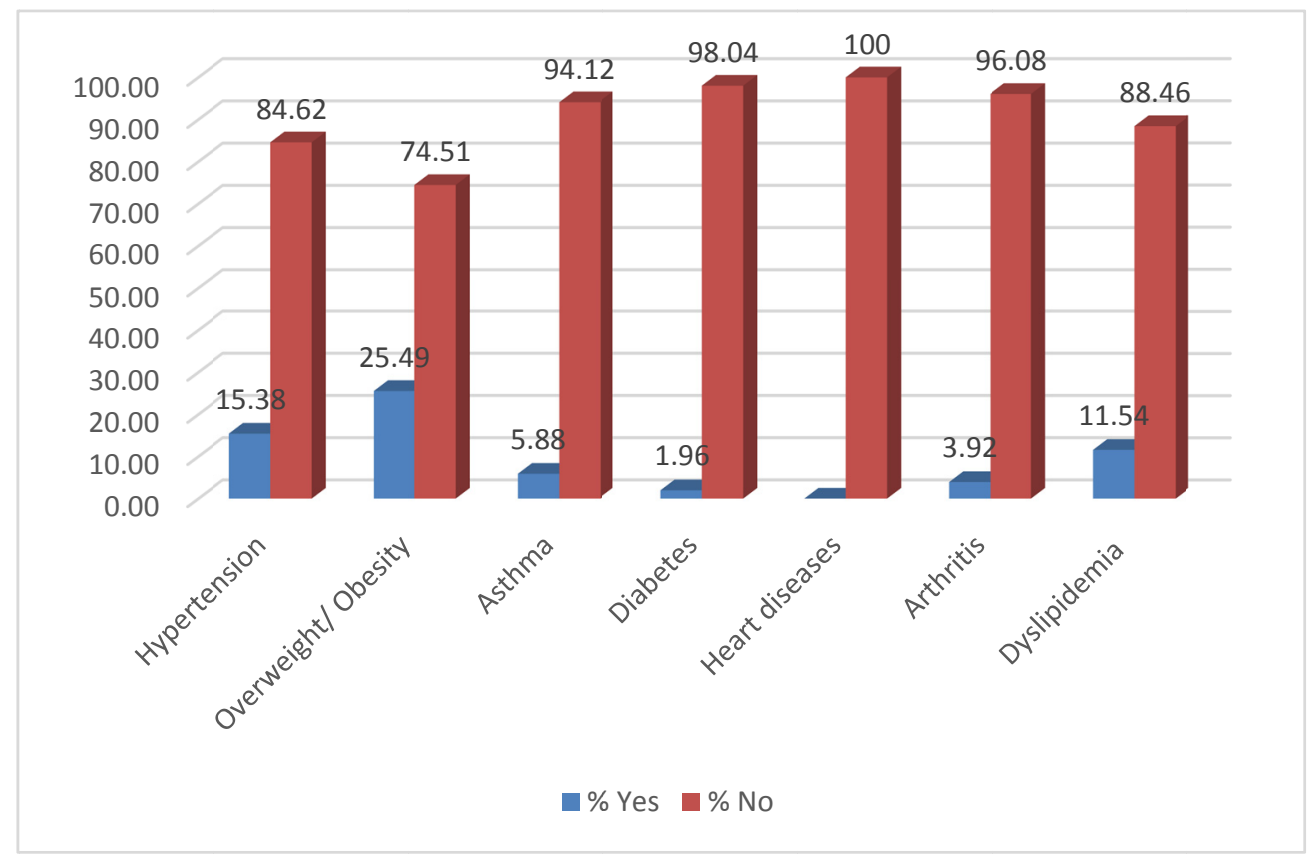

Figure 1. Distribution of the study group according to their existing health problems

As shown in the Figure 1, the faculty reported their existing health problems such as overweight $(25.4 \%)$ or obesity, hypertention (15.3\%), dyslipidemia (11.5\%), asthma (5.88\%), arthritis (3.92\%) and diabetes (1.96\%).

\section{Awareness of the respondants about their cholestrol, blood sugar and blood pressure levels}

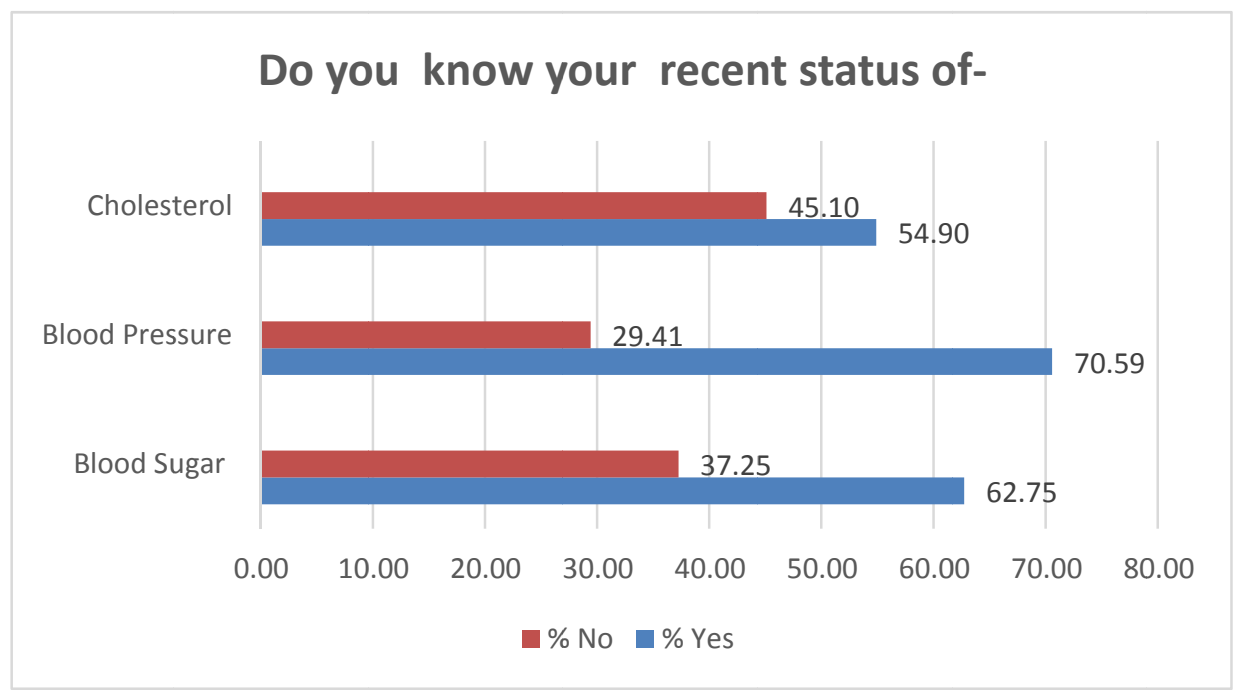


Figure 2. Distribution of the study group according to their awareness about Cholestrol, blood sugar and blood pressure levels

Figure 2 clarifies that majority of the faculty were aware of their blood suger $(62.75 \%)$, blood pressure $(70.59 \%)$ and cholestrol levels $(54.90 \%)$.

\section{Consumption of tobacco and alcohol among the faculty}

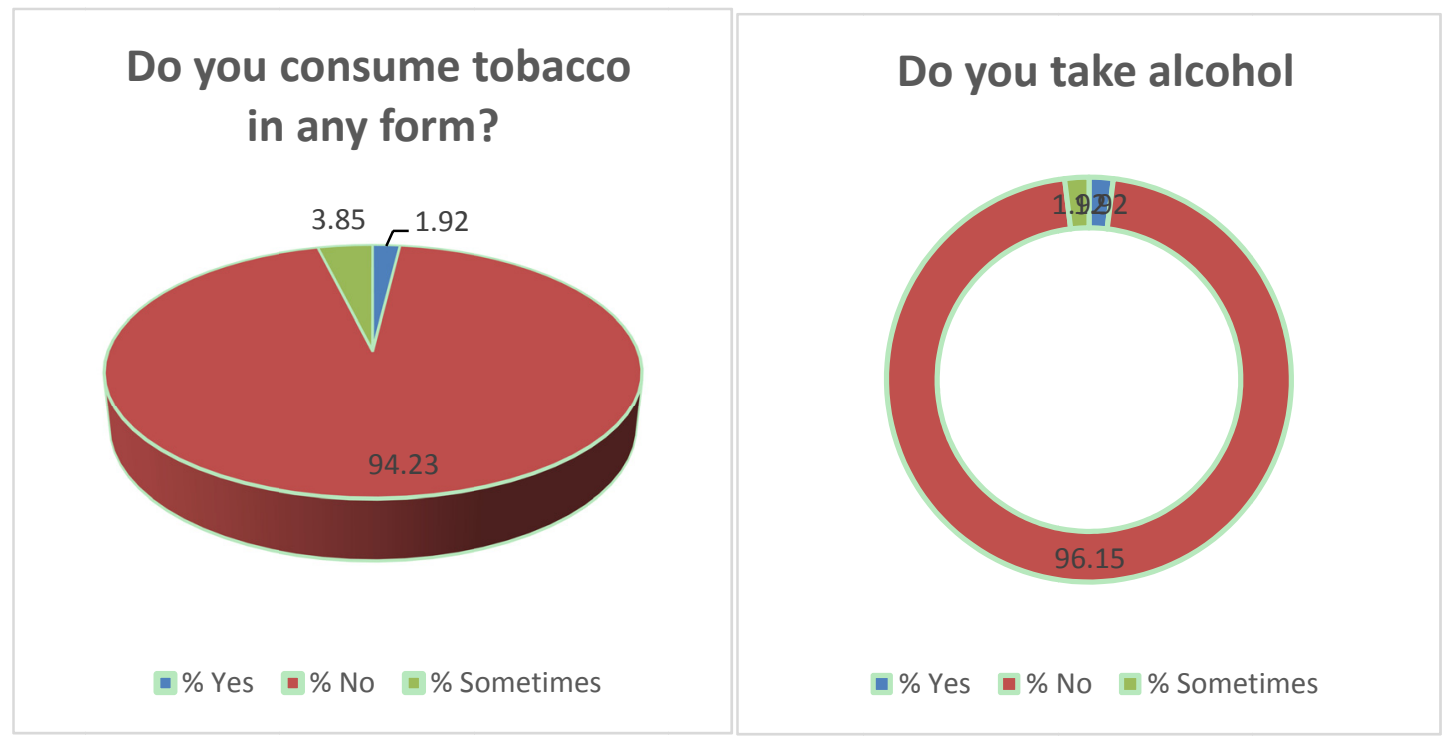

Figure 3. Distribution of the study group according to their consumption of tobacco and alcohol

Figure 3 shows that majority ( $94-96 \%$ ) of the faculty did not take alcohol and tobacco in any form. Section II: Perception of Health Promotion (PHP)

Table 2. Distribution of study group according to their perception of health promotion

\begin{tabular}{|c|c|c|c|c|c|}
\hline & $\begin{array}{l}\% \text { Strongly } \\
\text { disagree }\end{array}$ & $\begin{array}{c}\% \\
\text { Disagree }\end{array}$ & \% Can't say & $\%$ Agree & $\begin{array}{c}\% \% \\
\text { Strongly } \\
\text { Agree }\end{array}$ \\
\hline $\begin{array}{l}\text { Health promotion is most } \\
\text { important for healthy living }\end{array}$ & 0.00 & 0.00 & 1.92 & 23.08 & 75.00 \\
\hline $\begin{array}{l}\text { I believe my health is the best } \\
\text { resource for my everyday life }\end{array}$ & 0.00 & 0.00 & 0.00 & 19.23 & 80.77 \\
\hline $\begin{array}{l}\text { I believe my health promotion } \\
\text { activities will keep me healthy } \\
\& \text { give me younger looks }\end{array}$ & 0.00 & 0.00 & 5.77 & 32.69 & 61.54 \\
\hline $\begin{array}{l}\text { I feel responsible to perform } \\
\text { my health promotion activities }\end{array}$ & 0.00 & 0.00 & 3.85 & 42.31 & 53.85 \\
\hline $\begin{array}{l}\text { I do not find time to do my } \\
\text { physical exercises daily }\end{array}$ & 10.00 & 24.00 & 6.00 & 50.00 & 10.00 \\
\hline $\begin{array}{l}\text { Morning time is too busy time } \\
\text { for me to perform physical } \\
\text { exercises \& Yoga }\end{array}$ & 5.77 & 15.38 & 5.77 & 36.54 & 36.54 \\
\hline $\begin{array}{l}\text { At the end of the day, I am tired } \\
\text { to perform physical exercises }\end{array}$ & 7.84 & 21.57 & 5.88 & 31.37 & 33.33 \\
\hline $\begin{array}{l}\text { I am able to choose the best } \\
\text { health promotion activity for } \\
\text { my self }\end{array}$ & 1.92 & 3.85 & 30.77 & 40.38 & 23.08 \\
\hline
\end{tabular}




\begin{tabular}{|c|c|c|c|c|c|}
\hline $\begin{array}{l}\text { I feel health promotion } \\
\text { activities actually do not } \\
\text { promote health }\end{array}$ & 40.38 & 48.08 & 3.85 & 3.85 & 3.85 \\
\hline $\begin{array}{l}\text { I believe that adequate sleep of } \\
7-9 \text { hours is must for an adult }\end{array}$ & 1.92 & 5.77 & 5.77 & 38.46 & 48.08 \\
\hline $\begin{array}{l}\text { I often face sleeplessness } \\
\text { problem }\end{array}$ & 22.00 & 40.00 & 8.00 & 22.00 & 8.00 \\
\hline $\begin{array}{l}\text { I feel my work is very stressful } \\
\text { with lot of environmental } \\
\text { stressors }\end{array}$ & 13.73 & 31.37 & 21.57 & 23.53 & 9.80 \\
\hline $\begin{array}{l}\text { Though the health promotion is } \\
\text { most important, I am not able } \\
\text { to perform my daily physical } \\
\text { activities due to my family \& } \\
\text { work responsibilities }\end{array}$ & 11.54 & 32.69 & 13.46 & 25.00 & 17.31 \\
\hline $\begin{array}{l}\text { Though the health promotion is } \\
\text { most important, I am not able } \\
\text { to perform my daily physical } \\
\text { activities due to my health } \\
\text { problems }\end{array}$ & 36.54 & 44.23 & 11.54 & 5.77 & 1.92 \\
\hline $\begin{array}{l}\text { I believe that one should } \\
\text { restrict eating sweets and fried } \\
\text { foods }\end{array}$ & 1.92 & 9.62 & 5.77 & 44.23 & 38.46 \\
\hline $\begin{array}{l}\text { Junk food should } \\
\text { completely } \\
\text { our diet }\end{array}$ & 0.00 & 17.31 & 9.62 & 36.54 & 36.54 \\
\hline $\begin{array}{l}\text { I feel I am overweight but } 2 \mathrm{t} \\
\text { able to maintain my weight }\end{array}$ & 40.38 & 15.38 & 15.38 & 21.15 & 7.69 \\
\hline
\end{tabular}

Majority (98\%) of the participant felt that health promotion is most important for healthy living and perceived that health is the best resource for everyday life $(100 \%)$. They felt that their health promotion activities will keep them healthy and give them younger looks (94\%). As far as performing health promotion activities for self is concerned, the faculty felt that they themselves are responsible to perform health promotion activities $(96 \%)$ However majority $(60 \%)$ of the faculty were of the view that they do not find time to do physical exercises daily. They also perceived that health promotion activities actually promote health $(88 \%)$ and believed that adequate sleep of 7-9 hours is must for an adult ( $86.54 \%)$, though some of the faculty often face sleeplessness problem $(30 \%)$ and felt that their work is very stressful with lot of environmental stressors $(33.33 \%)$.

\section{Health promotion perception level}

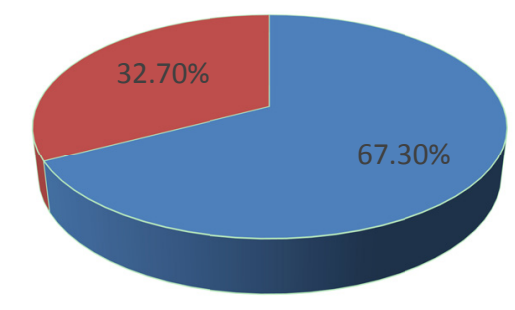

- Satisfactory - Unsatisfactory

Figure 4. Distribution of the study group according to their health promotion perception level

Overall (Figure 4) more than two-third (67.3\%) of the study group had a satisfactory level of perception while 
around one-third (32.7\%) had unsatisfactory level. Mean \& standard deviation of the health promotion perception level was $59.67 \pm 7.28$.

\section{Section III: A. Health Promotion Practices (HPP)}

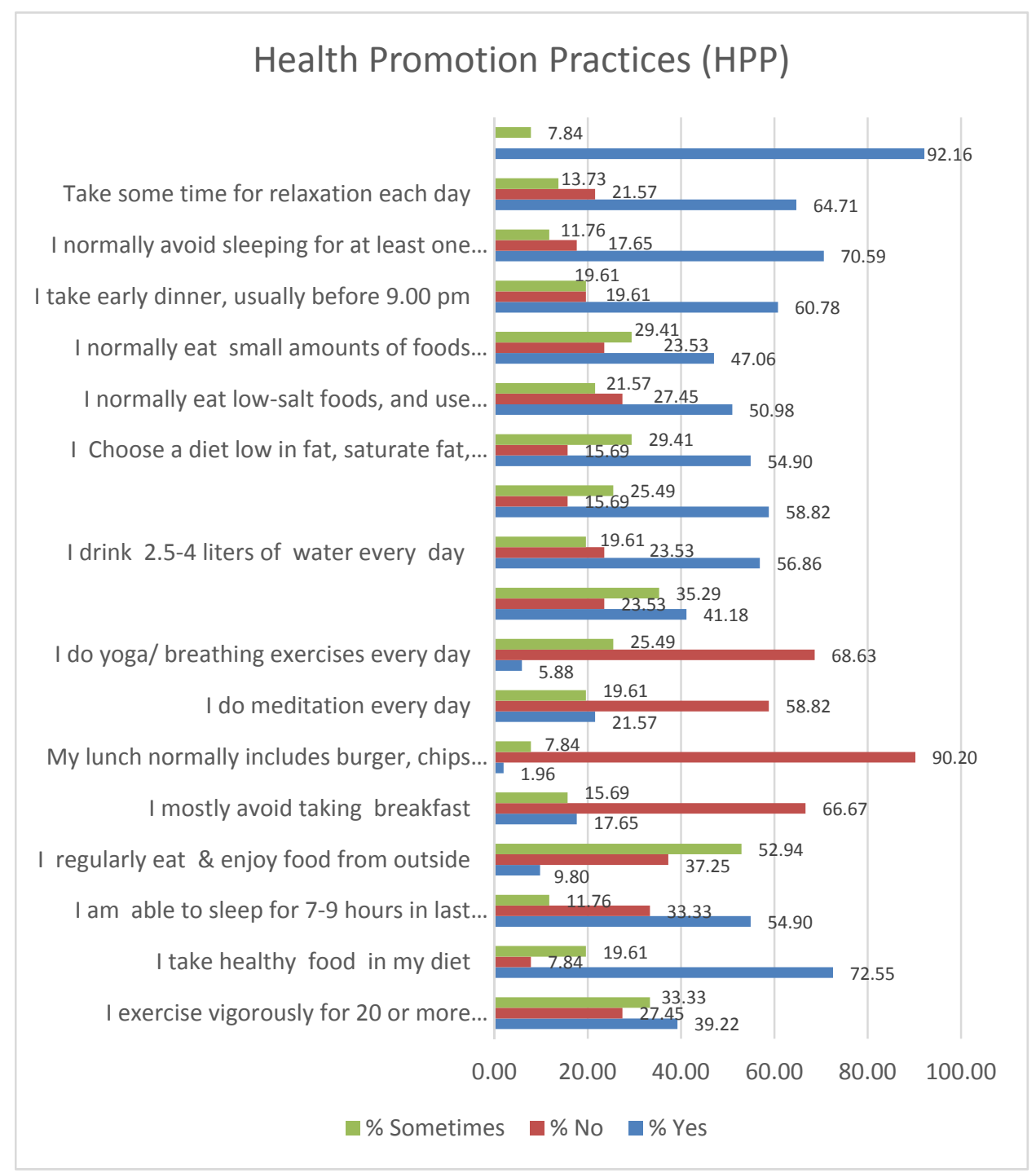

Figure 5. Distribution of the study group according to their health promotion practice

As shown in figure 5, majority of the faculty maintained good inter-personal relationship with everyone at home and at work place $(92.16 \%)$, eat healthy food $(72.55 \%)$, take early dinner, (60.78), avoid sleeping for at least one hour immediately after full meal $(70.59 \%)$, take some time for relaxation each day $(64.71 \%)$, include plenty of wholegrain and fruit, vegetables and legumes in diet $(58.82 \%)$. However only $54.90 \%$ were able to sleep for 7-9 hours in last two weeks, drink 2.5-4 liters of water every day (56.86\%), About $59 \%$ of the faculty stated that they mostly choose diet low in fat especially saturated fat, and cholesterol (54.90\%), they normally eat low-salt foods, use salt sparingly (50.98\%) and eat small amounts of foods that contains added sugars (47.06\%).

\section{Health promotion practice levels of the faculty}




\section{Health promotion practice level}

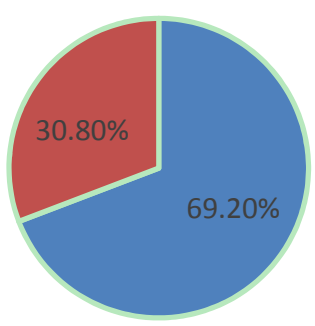

- Satisfactory

Figure 6. Distribution of the study group according to their health promotion practice levels

As shown in Figure 7, more than two-third (69.2\%) had satisfactory levels of health promotion while less than one-third had unsatisfactory level of practice. Mean \& standard deviation of the health promotion practice levels of the faculty is $38.73 \pm 5.79$.

\section{Section III: B. Regular practice of physical exercises}

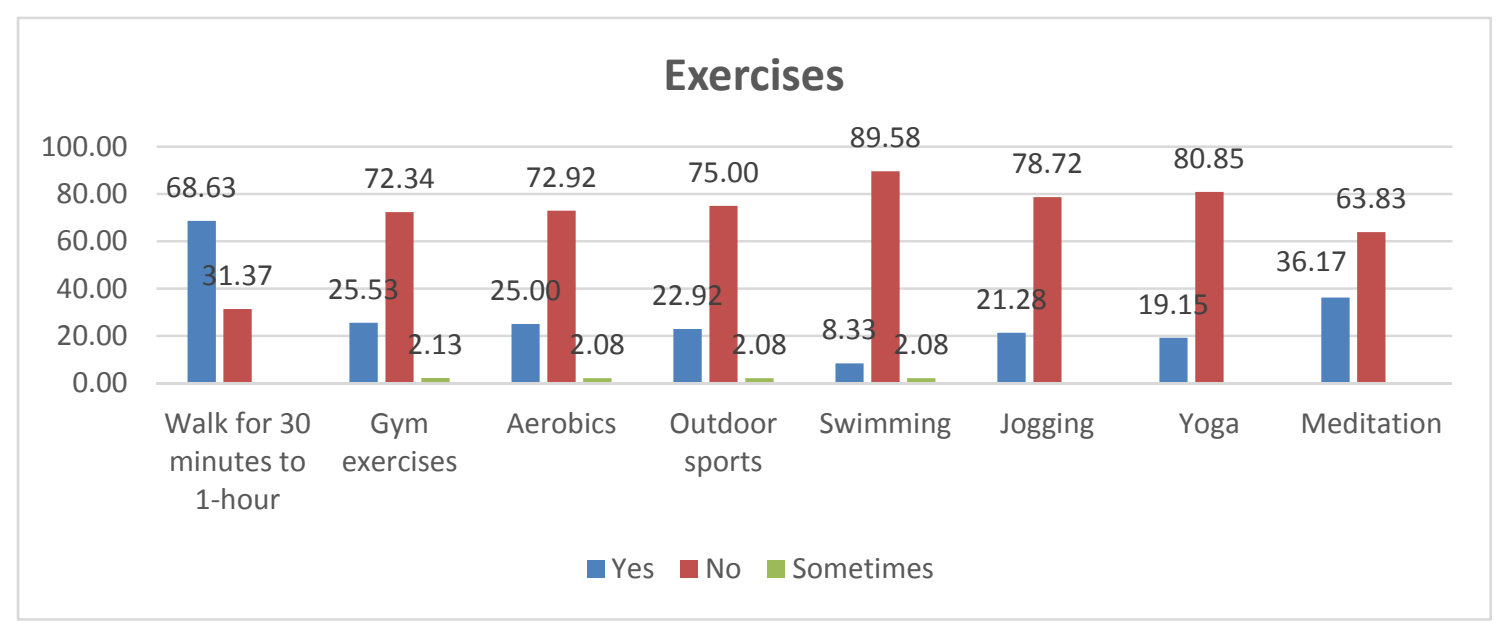

Figure 7. Distribution of the study group according to their regular practice of physical exercises

Figure 7 shows the physical exercises faculty practiced regularly included walking for 30 minutes to one hour (68.63\%), meditation (36.17\%), gym exercises (25.53\%), aerobics (25\%), outdoor sports (23\%), swimming $(8.33 \%)$, jogging (21. 28\%) and yoga (19.15\%).

Section IV: A. Association between selected demographic variables and health promotion perception among the faculty of Ras Al Khaimah Medical and Health Sciences University

Table 2. Distribution of the study group according to the association between selected demographic variables and health promotion perception levels

\begin{tabular}{llll}
\hline Item & \multicolumn{2}{c}{ Health promotion perception level } & $\mathrm{X}^{2}$ \\
\cline { 2 - 3 } & U-Value \\
& Unsatisfactory & Satisfactory & \\
\hline
\end{tabular}




\begin{tabular}{|c|c|c|c|c|c|}
\hline & $\mathrm{N}$ & $\%$ & $\mathrm{~N}$ & $\%$ & \\
\hline \multicolumn{6}{|l|}{ Faculty } \\
\hline Medical & 7 & 41.2 & 7 & 20.0 & \multirow{4}{*}{$\begin{array}{l}3.097^{\mathrm{a}} \\
>0.05\end{array}$} \\
\hline Nursing & 6 & 35.3 & 13 & 37.1 & \\
\hline Pharmacy & 2 & 11.8 & 7 & 20.0 & \\
\hline Dental & 2 & 11.8 & 8 & 22.9 & \\
\hline \multicolumn{6}{|l|}{ Age / years } \\
\hline$<40$ & 10 & 58.8 & 17 & 48.6 & \multirow{2}{*}{$0.562 *$} \\
\hline$\geq 40$ & 7 & 41.2 & 18 & 51.4 & \\
\hline \multicolumn{6}{|l|}{ Gender } \\
\hline Male & 8 & 47.1 & 11 & 31.4 & \multirow[t]{2}{*}{$0.360^{*}$} \\
\hline Female & 9 & 52.9 & 24 & 68.6 & \\
\hline \multicolumn{6}{|c|}{ Marital status } \\
\hline Married & 16 & 94.1 & 29 & 82.9 & \multirow[t]{2}{*}{$0.404 *$} \\
\hline Unmarried & 1 & 5.9 & 6 & 17.1 & \\
\hline \multicolumn{6}{|l|}{ Ethnicity } \\
\hline Arab & 1 & 5.9 & 11 & 31.4 & \multirow[t]{2}{*}{$0.076^{*}$} \\
\hline Non-Arab & 16 & 94.1 & 24 & 68.6 & \\
\hline \multicolumn{6}{|c|}{ Years of experience } \\
\hline$<5$ & 10 & 58.8 & 18 & 51.4 & \multirow[t]{2}{*}{$0.769 *$} \\
\hline$\geq 5$ & 7 & 41.2 & 17 & 48.6 & \\
\hline
\end{tabular}

*fisher exact test

It is clear from the Table 2 that there is no significant association between the selected demographic variables and health promotion perception levels among the faculty of Ras Al Khaimah Medical and Health Sciences University

B. Association between selected demographic variables and health promotion practices among the faculty of Ras Al Khaimah Medical and Health Sciences Universi

Table 3. Distribution of the study group according to association between selected demographic variables and health promotion practice levels

\begin{tabular}{|c|c|c|c|c|c|}
\hline \multirow[t]{3}{*}{ Item } & \multicolumn{4}{|c|}{ Health promotion practice level } & \multirow{3}{*}{$\underset{\mathrm{P}-\text { Value }}{\mathrm{X}^{2}}$} \\
\hline & \multicolumn{2}{|c|}{ Unsatisfactory(16) } & \multicolumn{2}{|c|}{ Satisfactory(36) } & \\
\hline & $\mathrm{N}$ & $\%$ & $\mathrm{~N}$ & $\%$ & \\
\hline \multicolumn{6}{|l|}{ Faculty } \\
\hline Medical & 3 & 18.8 & 11 & 30.6 & \multirow{4}{*}{$\begin{array}{l}5.070^{\mathrm{a}} \\
>0.05\end{array}$} \\
\hline Nursing & 5 & 31.3 & 14 & 38.9 & \\
\hline Pharmacy & 2 & 12.5 & 7 & 19.4 & \\
\hline Dental & 6 & 37.5 & 4 & 11.1 & \\
\hline \multicolumn{6}{|l|}{ Age / years } \\
\hline$<40$ & 11 & 68.8 & 16 & 44.4 & \multirow[t]{2}{*}{$0.138 *$} \\
\hline$\geq 40$ & 5 & 31.3 & 20 & 55.6 & \\
\hline \multicolumn{6}{|l|}{ Gender } \\
\hline$\overline{\text { Male }}$ & 6 & 37.5 & 13 & 36.1 & \multirow[t]{2}{*}{$1.000^{*}$} \\
\hline Female & 10 & 62.5 & 23 & 63.9 & \\
\hline \multicolumn{6}{|c|}{ Marital status } \\
\hline Married & 14 & 87.5 & 31 & 86.1 & \multirow[t]{2}{*}{$1.000 *$} \\
\hline Unmarried & 2 & 12.5 & 5 & 13.9 & \\
\hline \multicolumn{6}{|l|}{ Ethnicity } \\
\hline$\overline{A r a b}$ & 6 & 37.5 & 6 & 16.7 & \multirow[t]{2}{*}{$0.153 *$} \\
\hline Non-Arab & 10 & 62.5 & 30 & 83.3 & \\
\hline \multicolumn{6}{|c|}{ Years of experience } \\
\hline$<5$ & 11 & 68.8 & 17 & 47.2 & \multirow[t]{2}{*}{$0.229 *$} \\
\hline$\geq 5$ & 5 & 31.3 & 19 & 52.8 & \\
\hline
\end{tabular}


*fisher exact test

It is clear from the Table 3 that there is no significant association between the selected demographic variables and health promotion practices among the faculty of Ras Al Khaimah Medical and Health Sciences University.

\section{Discussion}

Health promotion is prime important activity for healthy living. The health care professionals are expected to teach the common public about importance and practice of health promotion. To urge others to practice, the health care professional must practice this aspect for themselves. (Wolf, 1994)

The faculty of health sciences university train the health care professionals. Their understanding and practice of health promotion therefore was the concern of this study.

The results of the study indicate that the faculty understands importance of health promotion for healthy living and they know that the self-health promotion is their own responsibility. The faculty also felt that they can choose the best health promotion activity for themselves. In spite of this, the majority of the faculty were not able to perform their physical exercises daily due to time constraint, family and work responsibilities and due to their own health problems. The faculty reported that their morning time is too busy time for them to perform physical exercises and at the end of the day, they feel tired to perform physical exercises. Lack of time to perform health promotion activities by the employees were also reported by Brayer, Cherkis, and Roman, (2013).

Though about $55 \%$ of the faculty reported taking adequate sleep there were $45 \%$ of the faculty suffering with sleeplessness problem and related it to stressful work and other environmental stressors. Sleeplessness problems among the health care professionals including students is one of the major problem was also identified by Yasin, Muntham and Chirakalwasan (2016). The faculty believed that eating sweets and fried foods is not good for health and junk food should be completely eliminated from diet. The faculty with the problem of overweight reported that reducing weight is the major problem for them and they are not able to maintain their weight with their regular efforts.

Not restricting the intake of salt is also one alarming dietary practice and only $50 \%$ of the faculty was found to be consuming low salt food. The longer sitting hours (6-10 hours) was reported by most of the faculty. Sitting for longer hours is detrimental to health and increases the cardiovascular and metabolic risk along with risk to musculoskeletal health.as reported by Baker, Williamson, \& Straker (2018) in their study. Lack of physical exercises and sitting for longer hours may increase the problem of overweight and obesity among the faculty.

In spite of having knowledge about importance of health promotion, only $39 \%$ of the faculty were actually able to practice the exercise such as brisk walking, bicycling, aerobic dancing, and swimming vigorously for 20 or more minutes at least three times a week. Another important practice related to eating meals that is not favorable to health is that some faculty (18\%) were mostly avoiding taking breakfast, regularly eat and enjoy food from outside ( $10 \%)$, and were eating junk foods like burger, chips and soft drinks in lunch (2\%).

The health promotion aspects related to physical mobility were not mostly practiced by the faculty such as daily exercises, meditation, yoga/ breathing exercises etc. Vey less percentage of the faculty were found to be consuming adequate fruits \& vegetables and drink sufficient amount of water every day. So it can be concluded that though most of the dietary precautions are followed by the majority faculty, their nature of work is mostly sedentary and proportionately they do not perform physical activities adequately.

\section{Conclusion}

The study indicated that though health promotion is perceived as most important factor for healthy living, still it is not practiced in day to day life by the majority of the faculty. There is a great need to motivate people at all levels towards the practice of health promotion which is of vital importance in improving quality of life and preventing the noncommunicable diseases which are the major threat to peoples' life. The university faculty mostly have sedentary job and sit for longer hours without performing any physical activity. Controlling diet alone will not help in health promotion .A concerted and comprehensive practice of physical activities along with healthy and balanced diet with application of stress reduction measures at workplace are of prime importance to health promotion.

\section{Recommendation}

Based on this study, following recommendations are suggested:

1. Similar study can be conducted on larger sample involving different setting such as universities, hospitals and primary health centers to assess perception, attitude and practices of health care professionals towards health promotion 
2. There is a great need to motivate the health care professionals about performing regular health promotion activities. The faculty needs to utilize the existing gyms and sports facilities of the university. Based on this more interventional studies could be planned to evaluate its effectiveness.

3. Extensive study involving the students and faculty of the constituent colleges of all seven Emirates could be undertaken to assess their existing health promotion practices

4. More qualitative and quantitative studies to be carried out to assess the cultural and traditional beliefs of people in performing their health promotion practices

5. The interventional studies may be undertaken to identify the effect of health promotion activities on health and well- being of the faculty.

\section{Limitations}

The study was restricted to one university hence has limitations in generalization

\section{Acknowledgement}

Authors would like to acknowledge the President, the Chief Academic Office and the faculty of the University who participated in the study.

Conflict of Interest Disclosure: Authors declare that there is no conflict of interest statement

\section{References}

Action, G. J., \& Malathun, P. (2000). Basic need status and health-promoting self-care behavior in adults. Western Journal of Nursing Research, 22(7), 796-811.

Amuna, P., \& Zotor, F. B. (2008). Epidemiological and nutrition transition in developing countries: impact on human health and development. The Proceedings of the Nutrition Society; Cambridge, 67(1), 82-90.

Arena, R., Guazzi, M., Lianov, L., Whitsel, L., Berra, K., Lavie, C. J., ... Shurney, D. (2015). Healthy Lifestyle Interventions to Combat Noncommunicable Disease - A Novel Nonhierarchical Connectivity Model for Key Stakeholders: a policy statement from the American Heart Association, European Society of Cardiology, European Association for Cardiovascular Prevention and Rehabilitation, and American College of Preventive Medicine. European Heart Journal, 36(31), 2097-2109. https://doi.org/10.1093/eurheartj/ehv207

Baker, R. C., PHE, Williamson, A., \& Straker, L. (2018). The Short Term Musculoskeletal and Cognitive Effects of Prolonged Sitting During Office Computer Work. International Journal of Environmental Research and Public Health, 15(8), 1678. https://doi.org/10.3390/ijerph15081678

Bakhshi, S., Sun, F., Murrells, T., \& While, A. (2015). Nurses' health behaviours and physical activity-related health-promotion practices. British Journal of Community Nursing, 20(6).

Bazargan, M., Makar, M., Bazargan-Hejazi, S., Ani, C., \& Wolf, K. E. (2009). Preventive, Lifestyle, and Personal Health Behaviors among Physicians. Academic Psychiatry, 3(4), 289-295.

Brayer, J., Cherkis, F., \& Roman, J. (2013). Health-promotion behaviors of undergraduate nursing students: A survey analysis. Nursing Education Perspectives, 34(6), 410-5.

Danaei, G., Ding, E. L., Mozaffarian, D., Taylor, B., Rehm, J., Murry, C. J. L., \& Ezzati, M. (2009). The preventable causes of death in the United States: Comparative risk assessment of dietary, lifestyle, and metabolic risk factors. PLOS Medicine, e1000058. https://doi.org/10.1371/journal.pmed.1000058

Frank, E., Dresner, Y., Shani, M., \& Vinker, S. (2013). The association between physicians' and patients' preventive health practices. CMJI, 185(8), 649-653. https://doi.org/10.1503/cmaj.121028

Gayle, A., \& Porntip, M. (2000). Basic need status and health-promoting self-care behavior in adults. Western Journal of Nursing Research, 22(7), 796-811.

Gross, C. P., Mead, L. A., Ford, D. E., \& Klag, M. J. (2000). Physician, heal thyself? Regular source of care and use of preventive health services among physicians. Arch Intern Med., 160(21), 3209-14. Retrieved October 12, 2018, from https://jamanetwork.com/journals/jamainternalmedicine/fullarticle/485562

Hedayat, N., Mojgan, J., Shorangiz, B., Mandana, S., Nasrin, A., \& et al.. (2016). The Prevalence of job stress and its relationship with burnout syndrome among the academic members of Lorestan university of medical sciences. Journal of Caring Science, 5(1), 75-84.

Ingibjörg, H., Jonsdottir, I. H., Börjesson, M., \& Gunnar Ahlborg, Jr. G. (2011). Healthcare workers' 
participation in a healthy-lifestyle-promotion project in western Sweden. BMC Public Health, 11, 448.

Karen, D., Hidalgo, K. D., Mielke, G. I., Parra, D. C., Lobelo, F., Simões, E. J., ... Hallal, P. C. (2016). Health promoting practices and personal lifestyle behaviors of Brazilian health professionals. BMC Public Health, 16,1114 .

Loprinzi, P. D., \& Beets, M. V. (2014). Need for increased promotion of physical activity by health care professionals. Prev Med., 69, 75-9. https://doi.org/10.1016/j.ypmed.2014.09.002

Shu-Ti, C., Jen-Huai, C., Nicole, H., \& Li-Yin, C. (2014). Health behaviors and participation in health promotion activities among hospital staff: which occupational group performs better?. BMC Health Services Research, 14, 474 .

Toyry, S., Rasanen, K., Kujala, S., Aarimaa, M., Juntunen, J., \& et al.. (2000). Self-reported health, illness, and self-care among finnish physicians: a national survey. Archives of Family Medicine, 9(10), 1079-85.

Walker, S. N., Sechrist, K. R., \& Pender, N. J. (1987). The Health-Promoting Lifestyle Profile: development and psychometric characteristics. Nursing Research, 36(2), 76-81.

Wolf, T. M. (1994). Stress, coping and health: enhancing well-being during medical school. Medical Education, 28(1), 8-17.

World Health Organization. (1996). The Ottawa Charter for Health Promotion. Retrieved from http://www.who.int/healthpromotion/conferences/previous/ottawa/en/

World Health Organization. (2017). Health Promotion. Retrieved from http://www.who.int/topics/health_promotion/en/

World Health Organization. (2018). Noncommunicable diseases: Country profile. Retrieved January 17, 2019, from file://G:/Z-To\%20discard/WHO-NCD\%20Profile.pdf

Yasin, R., Muntham, D., \& Chirakalwasan, N. (2016). Uncovering the sleep disorders among young doctors. Sleep Breath, 20, 1137-1144. https://doi.org/10.1007/s11325-016-1380-6

\section{Copyrights}

Copyright for this article is retained by the author(s), with first publication rights granted to the journal.

This is an open-access article distributed under the terms and conditions of the Creative Commons Attribution license (http://creativecommons.org/licenses/by/4.0/). 